\title{
TRIẾT LÍ VỀ BẢN CHẤT CỦA GIÁO DỤC TÙ QUAN ĐIỂM VĂN HÓA
}

The philosophy of nature of education from cultural view

Ngày nhận bài: 01/9/2016; ngày phản biện: 15/10/2015; ngày duyệt đăng: 21/11/2016

\section{Đặng Thành Hưng*}

\section{TÓM TẮT}

Sự phát triển của giáo dục luôn gắn liền với sự phát triển của lịch sử xã hội loài người. Đối với nhân loại, giáo dục là phương thức bảo tồn và bảo vệ kho tàng tri thức văn hoá xã hội. Bài viết này phân tích triết lí về bản chất của giáo dục từ quan điểm văn hóa.

Từ khóa: Giáo dục; văn hóa; triết lí giáo dục; quan điểm văn hóa

\section{ABSTRACT}

The development of education is always associated with the development of human social history. For humanity, education is a mode of preserving and protecting the treasure of cultural and social knowledge This article analyzes the philosophy of nature of education from cultural view culture.

Keywords: Education; culture; educational philosophy; cultural view

\section{Bối cảnh và vấn đề}

Giáo dục là hiện tượng thường được bàn đến ít nhất theo hai nghĩa: 1/đó là một trong những lĩnh vực tương đối độc lập của sự phát triển và tiến bộ kinh tế - xã hội; 2/là một hệ thống tác nghiệp chuyên môn, tức là dạy học và học tập, chương trình và học liệu, thầy và trò và những hoạt động, cơ cấu bảo đảm cho sự tác nghiệp này.

Các triết lí giáo dục cho dù nhiều đến đâu cũng có hai loại tương tự như hai kiểu tư duy nói trên. Có các triết lí về chương trình và hoạt động giáo dục, tức là những triết lí về hoạt động chuyên môn của nghề này, thí dụ như Dạy con tù thuở còn thơ. Và có các triết lí về sự phát triển giáo dục, thí dụ như Giáo dục là lĩnh vục đầu tư phát triển. Loại triết lí thứ hai nhằm lí giải bản chất của giáo dục từ các khía cạnh kinh tế - xã hội trên cơ sở nhận thức khoa học và nhận thức kinh nghiệm về các quan hệ khác nhau giữa giáo dục, phát triển giáo dục và phát

*Phó Giáo sư, Tiến sĩ - Trường Đại học Sư phạm Hà Nội 2 triển kinh tế - xã hội nói chung.

Chẳng hạn đó là các quan hệ: giáo dục và văn hóa, giáo dục và kinh tế, giáo dục và khoa học, giáo dục và phát triển con người, giáo dục và chính trị v.v..., cũng như các quan hệ kinh tế - xã hội vĩ mô với tư cách các phạm trù triết học thể hiện trong giáo dục như thế nào, thí dụ quan hệ lượng - chất, quan hệ khả năng - hiện thực, quan hệ chung - riêng...

Thường khi nói về bản chất của sự vật, người ta bàn đến thực thể, cấu trúc, chức năng và các nguyên lí vận động của nó bởi vì qua phân tích những phạm trù này sẽ làm bộc lộ bản chất và qui luật của những quan hệ vĩ mô đã nêu ở trên. Sau đây, tôi xin đề cập một vài vấn đề đã đặt ra như là những triết lí chung nhất về bản chất của giáo dục từ quan điểm văn hóa.

\section{Nội dung nghiên cứu}

2.1. Triết lí tổng quát về bản chất giáo dục

Giáo dục là môi trường nhân văn trong 
đó diễn ra quá trình xã hội hóa cá nhân phù hợp với những định chế tư tưởng, chính trị, kinh tế, đạo đức và văn hóa của xã hội, dẫn đến kết quả là sự phát triển cá nhân của người học, của con người, và tiến bộ kinh tế - xã hội bền vững của quốc gia và thời đại.

Giáo dục có sứ mạng là phát hiện, nuôi dưỡng và phát triển nguồn nhân lực quốc gia, nhân tài của xã hội và không ngừng nâng cao tiềm năng trí tuệ của cộng đồng dân tộc để phát triển đất nước với tầm nhìn chung là vươn tới tự do, xã hội hiện đại, với các công dân có khả năng học tập thường xuyên, chủ động và tích cực sáng tạo trong môi trường sống và trong cuộc sống.

Mỗi người đều có cách hiểu và diễn đạt của riêng mình, và trên đây chỉ là một cách. Nếu gọn hơn chỉ cần nói: giáo dục là phương thức giao hòa giữa cá nhân và hệ thống văn hóa theo nguyên lí phát triển và nguyên lí chuyển đổi giá trị. Hoặc nói cách khác nữa: giáo dục là hình thức phổ biến của sự phát triển giữa con người và xã hội, bởi vì ngoài hình thức phát triển cá biệt do gen qui định thì ai cũng phải phát triển dưới hình thức chung nữa - giáo dục.

\subsection{Mục tiêu giáo dục quốc gia}

Con người cá nhân phát triển hài hòa, khỏe mạnh về thể chất, tâm lí và xã hội, có đức tin vào cái Thiện, vào con người và tương lai tốt đẹp của loài người, và những thế hệ người phát triển bền vững trên cơ sở hiểu biết nhau, biết hợp tác, chung sống và làm việc hiệu quả, vì lợi ích của mình và của Tổ quốc, của nhân loại, công bằng về cơ hội và khác biệt về thành tựu phát triển.

Nhìn chung cho dù có những khác biệt chính trị, kinh tế... giữa các quốc gia thì từ góc độ văn hóa vẫn có thể hiểu mục tiêu giáo dục quốc gia cơ bản vẫn là phát triển con người với những nét đồng nhất và những nét khác biệt nhất định do ảnh hưởng của văn hóa loài người và nền văn hóa cụ thể.

\subsection{Chức năng cơ bản của giáo dục}

a) Giáo dục là công cụ phát triển người và phát triển kinh tế - xã hội, vì nó tạo ra nguồn lực đầu tư phát triển quyết định nhất trong số các nguồn lực phát triển, đó là nguồn lực người (chức năng công cụ trong phát triển).

b) Giáo dục thực hiện chức năng phục vụ và dịch vụ xã hội thông qua các hoạt động dạy học, học tập, chuyển giao và phát triển tri thức, đào tạo nhân lực, cung cấp sức lao động, từ đó phát triển tính cách, năng lực chung và chuyên biệt của cá nhân, cũng như kĩ năng sống và giải quyết vấn đề của mọi người trong các lĩnh vực kinh tế - xã hội.

c) Giáo dục thực hiện chức năng tái sản xuất, phát triển các giá trị xã hội thông qua quá trình cá nhân hóa những giá trị, kinh nghiệm của loài người để làm phong phú và không ngừng nâng cao những giá trị, kinh nghiệm đó tại những giai doạn lịch sử tiếp sau của cộng đồng. Đây là điều có thể gọi là chức năng di truyền văn hóa của giáo dục, phân biệt với di truyền sinh học.

d) Giáo dục thực hiện chức năng phúc lợi xã hội, dù là giáo dục phi lợi nhuận hay có lợi nhuận. Nó bảo đảm giá trị học vấn mà con người thụ hưởng thực sự là một phần quan trọng của hạnh phúc, của thành công và của quyền công dân bình đẳng của mỗi người trước tất cả mọi người trong xã hội.

\subsection{Những nguyên tắc cơ bản của giáo dục}

a) Giáo dục hướng vào con người (người học), vì lợi ích con người và vì sự phát triển tự do của người học. Điều này dễ hiểu vì những lợi ích

và sự phát triển con người là lẽ sống còn của giáo dục, và nhờ những yếu tố đó thì giáo dục mới tồn tại và phát triển được. 
b) Giáo dục cho mọi người và của mỗi người trên cơ sở nỗ lực chung của cộng đồng, nhà nước và cá nhân (công bằng xã hội và khác biệt cá nhân). Nguyên tắc này nhấn mạnh giáo dục không đơn giản là giá trị được cho không, và ai ai cũng đương nhiên hưởng thụ được. Ai có được cái gì thì người đó phải nỗ lực mà giành lấy, vì vậy kết quả giáo dục luôn là cái riêng ở từng cá nhân. Đây có thể được xem như qui luật của giáo dục.

c) Giáo dục là hệ thống mở và được điều tiết đồng thời bằng các qui luật của kinh tế thị trường cũng như bằng những can thiệp của nhà nước dựa vào thể chế, chính sách và chuẩn. Giáo dục không thể phát triển bên ngoài các tác động của qui luật giá trị, qui luật cung - cầu và qui luật cạnh tranh. Nhưng giáo dục nào cũng tự thân là thiết chế xã hội - chính trị của nhà nước cụ thể và có bản chất của một loại công cụ định hướng trong quản lí xã hội.

d) Giáo dục được thực hiện vì chất lượng cuộc sống và sự phát triển bền vững của xã hội và đất nước (định hướng $\mathrm{XHCN}$, bản sắc Việt Nam, chủ quyền quốc gia và độc lập dân tộc), cũng như vì hòa bình và hạnh phúc của toàn nhân loại. Nếu thiếu nguyên tắc này thì giáo dục vô nghĩa, nếu như có sự phát triển giáo dục thì đó là sự phát triển rỗng không, không có nội dung, không có giá trị.

e) Giáo dục tuân theo những nguyên lí nền tảng của chủ nghĩa Mác - Lê Nin và tư tưởng Hồ Chí Minh trong mọi hình thức và tiến trình phát triển của nó. Cho dù các loại hình trường lớp, các cơ cấu tổ chức, các hình thức sở hữu và quản lí giáo dục ở nước ta thay đổi thế nào thì chủ nghĩa Mác - Lê Nin và tư tưởng Hồ Chí Minh vẫn là nguyên tắc nền tảng của phát triển giáo dục.

f) Giáo dục phát triển bằng tiềm năng vật chất, trí tuệ và đạo đức của dân tộc cũng như bằng quá trình tiếp nhận có chọn lọc những yếu tố tiến bộ và hiện đại của loài người.
Trong giai đoạn hiện nay, giáo dục Việt Nam cần huy động mạnh mẽ tiềm năng trí tuệ và đạo đức để phát triển, trước hết trong đội ngũ nhân sự giáo dục và các gia đình, và huy động tiềm năng vật chất trong xã hội cũng như từ cộng đồng quốc tế.

g) Giáo dục được tổ chức và thực hiện trên cơ sở khoa học, gắn bó với đời sống xã hội, những thay đổi kinh tế, văn hóa, công nghệ trong nước và những xu thế tiến bộ của đời sống quốc tế. Những thay đổi lớn nhất trong thời đại ngày nay là toàn cầu hóa kinh tế, các giao dịch xuyên và liên quốc gia, các quan hệ đa văn hóa và tiếp biến văn hóa, các tác động của mạng thông tin toàn cầu dựa vào công nghệ số và tài nguyên internet, các thành tựu hiện đại của công nghệ sạch và công nghệ quản lí có khuynh hướng nhân văn.

\subsection{Hệ thống giáo dục}

a) Hệ thống giáo dục là thể hiện thực tiễn của cấu trúc và việc tổ chức giáo dục ở qui mô quốc gia. Tính hợp lí của cấu trúc và tính hiệu quả của tổ chức giáo dục cũng là một trong những tiêu chí chất lượng của hệ thống giáo dục, vì chúng ảnh hưởng rất rõ rệt đến việc tiến hành quá trình giáo dục và hiệu quả quản lí, hiệu quả hoạt động giáo dục.

b) Do nó là hệ thống nên hệ thống giáo dục cũng tuân theo các liên hệ và qui luật hệ thống. Với mỗi hệ điều kiện, cấu trúc và tổ chức nhất định, mỗi hệ thống giáo dục có khả năng giới hạn của nó mà không thể vượt quá giới hạn ấy. Khi nó vận hành quá công suất và vượt quá giới hạn này, thì khủng hoảng sẽ xảy ra. Tuy khủng hoảng có thể vẫn là một trong những phương thức phát triển, nhưng phát triển theo phương thức này chắc chắn là thiếu bền vững và phải trả giá đắt.

c) Chất lượng của hệ thống giáo dục được tạo ra từ chất lượng của tất cả những thành tố cấu thành nó: nhân sự, hạ tầng vật chất - kĩ thuật, thông tin, hoạt động giáo dục, học liệu, môi trường dạy học, cơ cấu và hoạt 
động quản lí, thành tích học tập và giảng dạy, hiệu quả trong quá trình giáo dục v.v... Nhưng đem gộp tất cả những thành tố đó lại thì không phải là chất lượng của hệ thống. Chất lượng của hệ thống còn phụ thuộc vào bối cảnh bên ngoài và hiệu lực, hiệu quả quản lí giáo dục từ phía nhà nước và xã hội.

d) Hệ thống giáo dục là bộ phần chủ đạo của toàn bộ nền giáo dục quốc gia. Vì vậy những thay đổi của hệ thống giáo dục có vai trò dẫn động và định hướng cho toàn bộ việc đổi mới giáo dục.

\section{Kết luận}

Triết lí giáo dục thực chất là cơ sở triết học của một nền giáo dục của một nước. Đó là quan điểm về vai trò, vị trí của giáo dục; đường lối, phương hướng phát triển; mục tiêu, nguyên lí giáo dục; là quan điểm tư tưởng chỉ đạo phát triển giáo dục. Nắm vững được triết lí về bản chất của giáo dục từ quan điểm văn hóa sẽ giúp chúng ta phát triển được giáo dục, đồng thời xây dựng được nền văn hóa Việt Nam tiên tiến, đậm đà bản sắc dân tộc trong bối cảnh toàn cầu hóa, hội nhập kinh tế quốc tế hiện nay.

\section{TÀI LIỆU THAM KHẢO}

1. Luật sửa đổi, bổ sung một số điều của Luật Giáo dục số 44/2009/QH12 của Quốc hội nước CHXHCNVN, Nxb Chính trị Quốc gia, H. 2012;

2. Văn kiện Đại hội Đảng cộng sản Việt Nam lần thứ XII (2016), Nxb Chính trị quốc gia, Hà Nội;

3. UNESCO (2003). World Data on Education, 4-th Edition. Paris;

4. Đặng Thành Hưng (2016). Văn hóa tổ chức và văn hóa nhà trường trong quản lí giáo dục. Tạp chí Khoa học Giáo dục, số 124 tháng 1/2016, tr. 10-12, 15;

5. Đặng Thành Hưng (2014). Tiếp cận quản lí giáo dục hiện đại, Tập 1, Đại học Sư phạm Hà Nội 2. 